Copyright 1920. By A. I. E. E.

\title{
HIGH-TENSION INSULATOR PORCELAIN
}

\author{
BY W. D. A. PEASLEE
}

Electrical Engineer, Jeffery Dewitt Insulator Co., Huntington, W. Va.

Porcelain used in the manufacture of high-tension insulators must meet certain requirements as to mechanical strength, ability to resist, sudden changes of temperature, porosity, homogeneity and temperature, coefficient of resistivity. A further suggestion as to the influences of the Piezo electric effect and the deterioration of seemingly perfect porcelain is presented with a brief discussion of the degree of progress made in the art to date.

\section{INTRODUCTION}

W

HILE in the case of transmission line insulators it is true that the design of the insulators insofar as the utilization of the material is concerned is a matter of most efficient design of air insulators, that is, the boundary surface between the air and the supporting dielectric, the material of the insulator itself becomes of greater importance as the voltage of the line increases.

The shape design of the insulator will not be discussed here as that subject is reserved for a later communication. It is hoped that the following discussion of the factors affecting the material employed in the manufacture of high-tension insulators as a dielectric, may lead engineers to a more serious consideration of this vitally important question. The discussion is confined to porcelain as for many reasons this material has come to be accepted as the best for high-tension insulators.

Factors to Be Considered in the SElection of a Porcelain Body as a Material FOR HighTENSION INSULATORS

Mechanical Strength. It is perfectly obvious that mechanical strength is one of the prime factors to be considered in an insulator material. One of the first duties of an insulator is to support the conductor, 
and it must do so under any conditions not severe enough to destroy some other element of the transmission line construction.

Insulators made today either in pin or suspension types, use porcelain either in compression or tension or both, and so it is of great importance to know the strength of porcelain under these conditions.

Porcelain being a brittle or rigid substance like cast iron, has no yield point as commonly known, and its first yield is complete rupture. There seems to be no indication that the stressing of porcelain to a point close to its ultimate strength injures it either mechanically or electrically. Indeed, the accumulated evidence of a large number of tests covering combined electrical and mechanical tests, fatigue tests and highfrequency tests indicate that such stressing has no effect whatever upon these properties. It is probably quite safe to say that properly vitrified porcelain must be stressed beyond its ultimate strength to rupture it even under repeated strains. Tension and compression tests both confirm this statement.

It is, therefore, immaterial whether the porcelain be used for compression or tension, provided that maximum momentary stress does not reach the ultimate strength of porcelain. For engineering reasons an ample safety factor must always be provided for. Ordinary porcelain, made up of the usual three ingredients, - clay, flint and feldspar- has been found by several investigators to have strengths reaching as a maximum 40,000 lb. per sq. in. for compression and $1500 \mathrm{lb}$. per sq. in. for tension. Naturally different proportions of these ingredients produce a porcelain, or to use a ceramic term, "Body," (which covers all bodies made up of the above or similar ingredients and vitrified) of somewhat different mechanical characteristics, but these figures cover rather the upper limit of strength for a body having the required characteristic as to dielectric qualities and ability to withstand sudden temperature changes.

The wide difference between these values has led many engineers to distrust porcelain used under tension, but provided the stresses are kept within 
the proper limits, from an engineering safety factor point of view, there is no more valid ground for this attitude than there is to condemn cast iron whenever used in tension.

Under the stimulus of the demand by transmission engineers for better insulation a great deal of work has been done on porcelain mixtures or bodies, and certain types are now available, whose strength runs up to $65,000 \mathrm{lb}$. per sq. in. in compression and 12,500 lb. per sq. in. in tension. This, indeed, is not the ultimate limit, as indications point to the commercial production of bodies with even greater strength which will at the same time retain the other necessary requirements.

In making tension and compression tests on porcelain it is very necessary that the application of the stress be made in such a manner as to place the porcelain either in pure compression or tension as desired. The compression tests are made on small blocks and the pressure applied through lead or blotting paper disks. The tension tests are made on test pieces consisting of a short, straight section of accurately determined area between two conical end pieces. These conical end pieces are gripped in a specially designed multiple part clutch faced with soft lead or blotting paper sheets; and remarkably consistent results are obtained in this manner.

Ability to Resist Sudden Changes in Temperature. A great many insulator failures are traceable directly to the inability of certain porcelain bodies to resist sudden changes in temperature. The first rays of sunlight on a frosty morning have often been the signal for insulator failures directly attributable to this weakness.

Also a body sensitive to this change is more difficult to manufacture reliably as it will develop internal strains which, added to the applied service strains; will produce rupture of the porcelain at very low applied loads. The existence of these strains has been shown by polarized light under microscopic examination.

Any mixture or body that in the shape and size employed will not, when completely equipped with 
hardware, withstand an indefinite number of alternate immersions in boiling and freezing water, should never be employed in the manufacture of high-tension insulators. This test should be insisted upon by purchasing engineers. Such bodies are made today, and some are made that will stand even greater ranges. At least two are known which can be heated red hot and thrown into a bucket of water without cracking.

Porosity. Porous porcelain is responsible to a large degree for the unsatisfactory condition of the insulator situation of today. One of the greatest insulator manufacturers has recently stated in a published article that non-porous porcelain cannot be produced.

This statement is challenged as the writer's investi-

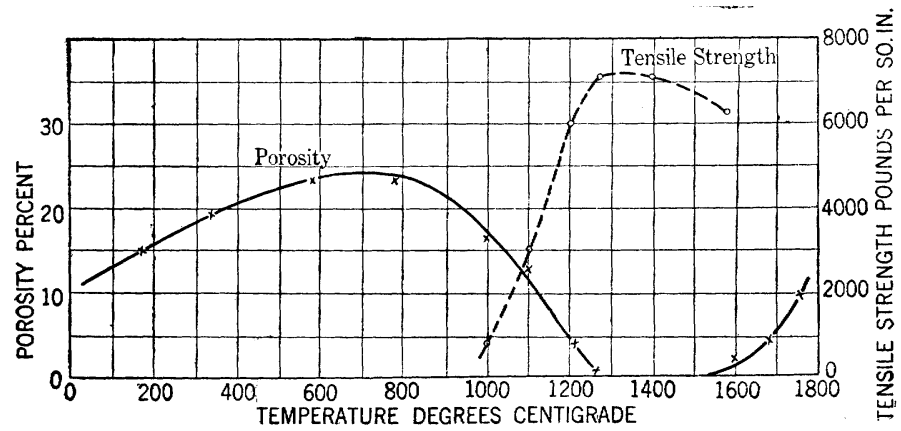

Fig. 1-Porosity and Tensile Strength CharacteristicsSpecial Porcelain Body

gations, both in this country and in the laboratories of France, indicate that it can be produced and under manufacturing conditions. Porcelain can be, and is, produced today that is in an engineering sense, absolutely non-porous. This statement is made after a great deal of careful research and on the strength of many porosity tests both by the impregnation method and the method used in ceramic analysis with a psychometer and a sample crushed to a 100-mesh fineness. The impregnation test has been carried in our laboratories to very high pressures, and is so penetrating that, under microscopic examination of the penetration of the colorant material, it has been observed in the cleavage cracks of microscopic quartz crystals.

Furthermore, a body having the slightest porosity, 
as indicated by the psychometer test, shows a decided penetration under the impregnation test.

Porosity is of two kinds, discussed in ceramic language as open pore and closed pore types. In the open pore type the pores or voids are connected by capillary passages, while in the second, or closed pore type, the voids or pores are isolated. Though the percentage of porosity may be the same in the two cases, it is obvious that the general character of porosity and its effect on insulators is different in the two cases. In general, the first form is a product of underfiring and the second of over-firing, though many instances have been found wherein over-firing produces the first type of porosity. There are probably many ceramists even today, who will dispute the statement that over-firing will produce porosity, but it can be very readily demonstrated by proper tests. In this connection the curve of Fig. 1 shows the behavior of one mixture or body and indicates very well the effect of the temperature of firing on the porosity of the body. The porosity developed on over-firing on this body was of the closed pore type and on under-firing of the open pore type. In securing the data for making this curve the samples were fired to given temperatures and cooled, and the porosity and tensile strength values were taken at room temperature. In other words the points on the curve represent maximum temperature of firing of each sample and not the temperature of the test. The porosity determinations were made by the psychometer method, the impregnation method being in any case merely qualitative.

In practise the effect of open pore type of porosity is too well-known to discuss here. The development of megger and buzz stick tests are ample evidence of the degree to which this factor has entered into the troubles encountered in the insulator field. Tests to determine porosity in units at the factory are needed, and the man who develops a method whereby we can detect porous insulators at the factory without destroying them, will be a true benefactor of the transmission engineers and porcelain manufacturers.

In the production of insulators a method has been 
developed that is very valuable in production control testing. A solution of fuchsine dye in wood alcohol is used and unglazed pieces placed in it under pressure. The slightest degree of porosity of the open pore type is indicated by a deep penetration of the dye into the body of the test piece. Indeed, as mentioned before, it is so penetrating that the microscope has shown it forced into the cleavage cracks of minute quartz crystals. If test pieces of the same shape and volume as the insulators being fired are properly distributed in the kiln the fuchsine test on these pieces will furnish a very reliable indication of the condition of neighboring pieces as to porosity.

Some very interesting developments have recently been brought out by the use of very high pressures on the solubility of porcelain in water under certain conditions, and it is probable that considerable light will soon be thrown upon certain types of insulator depreciation as a result of these developments.

It has been found possible to produce insulators of non-porous porcelain within the ordinary limits of quantity manufacture and by means of this method of control to prevent the porous insulators, a few of which are unavoidable in commercial manufacture, from going to the customers. Closed pore porosity is commonly indicated by a swelling of the insulators, and can be watched closely by gauges applied to the finished product.

Temperature Resistivity Coefficient. The temperature resistivity coefficient of porcelain is large and negative. The curves of Fig. 2 give an idea of this characteristic and of the improvement that has been made in it. The curve marked "Conventional Porcelain" in Fig. 2 is the standard mixture of clay, flint and feldspar, and the curve marked "New Body" is one of the recent developments, the formula for which naturally cannot be disclosed. In this curve the points on the curve represent measured resistance attained at the temperatures noted by the abscissas of the curve. For instance, a certain sample of conventional porcelain will have a resistance of two megohms at slightly over 700 degrees fahr. (371 deg. cent.) 
whereas the "New Body" in an exactly similar piece has a resistance of two megohms at 1160 degrees fahr. (627 deg. cent). These curves will give some idea of the progress that has been made in this respect. The importance of this feature has been discussed by various writers, and it must be stated here that this characteristic may be improved but will always be negative even in pure quartz. It has an important bearing on the mechanism of insulator failures under

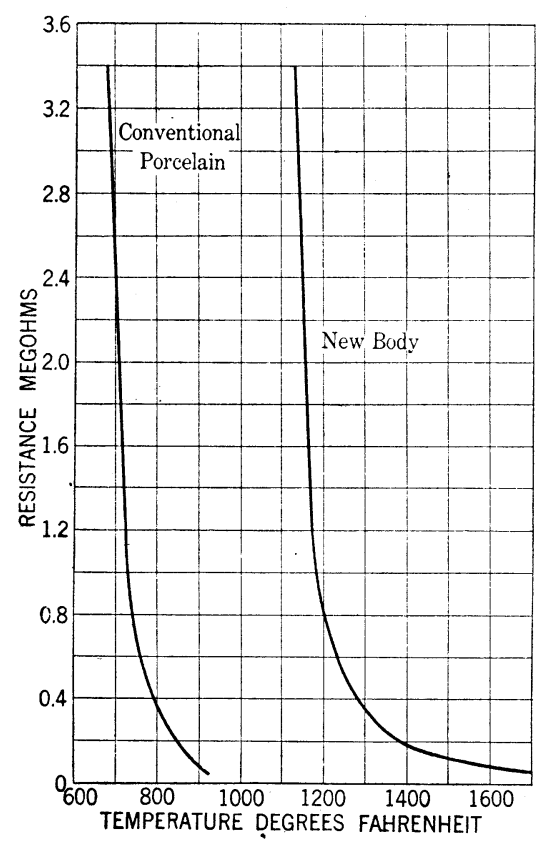

Fig. 2-Temperature Resistance Characteristics of Conventional and New Bodies

transient voltages. This has been discussed by the writer in previous papers before the institute. ${ }^{1}$

Piezo Electric Effect. One of the most baffling difficulties in the insulator situation is the deterioration of seemingly perfect units after a time, and the acquiring by non-porous porcelain of a certain porosity.

1. "Insulator Failures Under Transient Voltages," W. D. A. Peaslee, A. I. E. E. Transactions, page 1237, Vol. 35; "Insulator Situation....," W. D. A. Peaslee, A. I. E. E. TransACTIONs, page 401, Vol. 36. 
Some recent investigations indicate that this may be intimately connected with Piezo electric qualities of quartz crystals. Under the microscope it will be seen that porcelain as ordinarily made, consists of rather large particles of quartz in a vitreous magma. It is well-known that if certain crystals such as quartz are subjected to a pressure on two diametrically opposite faces which are parallel with the major axes, a potential difference is set up on the faces perpendicular to those upon which the pressure is applied, which varies directly as the pressure.

The converse of this is also true and if a difference of potential is applied to two opposite faces parallel to the major axes the crystal is subjected to a squeezing action and a change in dimensions of the crystal results. These changes in dimensions if strongly resisted by the surrounding magma will set up enormous local stresses between the magma and the crystals.

Now what happens when this porphyritic mass is placed in an alternating electro-static field? According to the theory of probabilities a large number of these quartz crystals are so arranged that their major axes are not parallel to the field of force. This alternating field applying potentials as described will set up in these crystals a change in mechanical dimensions 120 times per second in the case of a 60 -cycle system. This will result in a vibratory movement of these crystals. This vibratory action may be detrimental in two ways,- - first a rupture of the crystal itself, along cleavage planes, and second a rupture between the crystals and the surrounding magma.

A concentrated leakage current results through the spaces between the magma and the crystals when the crystal is at its greatest deformation and the potential differences are at maximum. It will also tend towards making the porcelain porous in an entirely different manner (that is, by cracks and fracture voids) from the types before mentioned and the vibratory action of the crystals may aid in the introduction of moisture into the body. This decreases its value as a dielectric and as mentioned before the solvent action of such 
moisture may have an accelerating effect upon the deterioration of the porcelain.

Regardless of the degree to which this effect contributes to the deterioration of the porcelain when in service on high-tension lines the body to be sought is one wherein the quartz is dissolved as completely as possible in the feldspathic magma.

Great progress has been made in this direction and in a later communication some data, which are now being prepared, may be given that it is hoped will be of some help in the solution of this ever present problem.

\section{CONCLUSION}

The insulator problem at present is one whose solution is to be sought in the ceramic field. Aside from more rational shape design on the part of electrical engineers, the improvement must come in the development of porcelain bodies which meet, to the greatest degree possible, the above requirements. Great progress has been made in this respect and the statement that we may very soon see the commercial production in insulator form of such bodies is now amply warranted. 
Discussion ON "High-TENION InsulatoR PoRCElaiN" (PEASleE), White SUlphuR Springs, W. VA., JunE 30, 1920.

H. B. Vincent: It seems to me there is too much insulation between the manufacturer and the electrical engineer, and not enough cooperation by the operating engineer in respect to keeping the records of practise and experience with insulators under operating conditions.

I had occasion within the last year to go into the insulator problem pretty thoroughly, due to the fact that quite a large order had to be placed for hightension insulators. Trouble had been experienced on some insulators which had been in service quite a while, but fortunately I had kept individual records of every broken high-tension insulator for six years, and on visiting the manufacturers, I found that record very valuable in coming to a conclusion as to what kind of insulator, I should buy. For example one insulator manufacturer, tried to impress very strongly on me that I should buy a certain type of insulator which he manufactured, mentioning the fact that some large company, which had been using it for years, had just duplicated the order. That would have made a very strong impression on me, had not my records failed to entirely substantiate his contention, probably due to the fact that the conditions under which I was operating were different from the conditions under which the other man was operating. I think the operating man should not lose sight of the fact that he is doing probably fifty per cent of the work of improving the product by keeping records, so that he can cooperate with the electrical engineers of the manufacturers, by giving them data of the actual performance of their insulator.

As another illustration I talked with an electrical engineer of a large operating company within the last month and was surprised to find that he was keeping no records, the apparent reason being he was not having much trouble, but I am inclined to feel, from my experience that in later years he may have trouble with his insulators, and then he will regret that he did not keep these records.

C. L. Fortescue: The insulator problem is quite a complicated one. It needs the cooperation of all the parties interested in obtaining good insulators. In dealing with the insulator problem we have to consider not only the problem of a clean insulator, but also the problem of the insulator which has been in 
service for a certain length of time consideration must be given also to the conditions of the line, etc.

There is one feature of the theoretical design that fits in admirably with this question of insulators that have been in service for sometime, that is, if the insulator is designed according to these principles, the intensity is tangential to the actual working surface, and consequently dirt does not accumulate thereon because there is no force tending to hold the particles of dirt onto the surface,- - the actual forces being such as to cause them to simply slide off the surface, and accumulate on the petticoats, what might be called the protective surfaces. Consequently, an insulator designed according to these principles will keep clean, and is to that extent self protective. For that reason besides many others the theoretical design produces a very good insulator.

I wish to emphasize one point brought out by the last speaker namely that we ought to take great pains to keep a record of insulators. There are many things that go towards making a good insulator, the quality of the porcelain is as important as the design and we should take pains not to allow prejudices to upset our judgment in respect to this important commodity. Let us see to it that we all cooperate.

R. M. Spurck: Mr. Peaslee has discussed a number of characteristics of porcelain as they relate to insulators. These characteristics, mechanical strength, ability to resist sudden temperature changes, porosity and temperature resistivity coefficient are all so closely related that all of them must be considered in any discussion of the characteristics of any specific sample of porcelain. For instance, a sample of porcelain with a high mechanical strength might be produced by sacrificing desirable porosity characteristics or ability to resist sudden changes of temperature. A discussion of the above mentioned characteristics especially as they apply to insulators should therefore include the characteristics as they apply to samples of identical materials, mixtures, manipulation, shape, drying and firing. To be a practical manufacturing proposition the mixture must produce, when all other conditions remain the same, a uniform product under a fairly broad range of firing temperatures. The importance of such characteristics is evident when it is known that kilns for commercial work cannot be depended upon to produce the same temperature in all parts, nor can they be fired to give exactly the same temperature at the same place for all runs.

The mechanical strength of porcelain both in tension 
and compression is difficult to determine. The values obtained depend not only on the fundamental characteristics of the material as determined by the materials, mixture, manipulation and firing but also upon the size and shape of the test piece. Tensile strength tests on a very short thin sample will give unit values that cannot be applied to longer samples of larger diameter. Unit tensile strength values obtained from samples where extra precautions were taken to eliminate bending stresses must not be applied to practical designs where it is not possible to take such precautions. Tests and samples of porcelain where $3000 \mathrm{lb}$. per sq. in. were obtained have been reported. ${ }^{1}$ The samples tested were 16 in. between grips and one inch in diameter. It is very probable that shorter samples would have given much higher values by the elimination of bending stresses. However, it is not believed that the unit stresses there obtained should be extended for use on samples of a much larger diameter.

The ability to resist such temperature changes is not only dependent upon the material itself, but also upon the shape and mass of the piece. This characteristic is also directly related to the temperature coefficient of expansion. The Bureau of Standards ${ }^{2}$ have recently published results of tests of a wide variety of porcelain mixtures on which the temperature coefficient of expansion from room temperature to a temperature of $200 \mathrm{deg}$. cent. varied from a minimum of $1.6 \times 10^{6}$ to a maximum of $19.6 \times 10^{6}$. It is interesting to note that the clay content of both samples was the same but the sample having the lowest coefficient contained 35 per cent of beryl.

The need for a method of determining the porosity of an insulator without destroying it is almost too evident to be discussed. There is also a need for a standard of porosity. Various investigators speak of a percent porosity but make no statement as to how the value is to be obtained.

The temperature resistivity coefficient of porcelain varies with the temperature of the material and also with the impressed voltage and time of application of voltage. Its independent relation to porcelain for line insulators appears to be somewhat doubtful. The fact that a piece of porcelain has a high specific resistance under certain conditions does not necessarily

1. "Boyd Elasticity and Strength of Porcelain and Stoneware." Journal of the American Society of Mechanical Engineers, March 1916.

2. Bulletin 352. "Thermal Expansion of Insulating Material.". 
imply that the porcelain is suitable for high-voltage insulators. The converse also appears to be true. Although it may be desirable for porcelain for line insulators to maintain an exceedingly high resistance at temperatures above $100 \mathrm{deg}$. cent., this seems to be improbable because there are no conditions of service where the insulators are operated at such a temperature.

Mr. Peaslee's curves in Fig. 2 show a wide variation in the temperature coefficient of resistance for two samples of porcelain. It is impossible, however, to compare his values with values obtained by other investigators because unit values are not given and the conditions of measurement are not listed. I would be interested to know how the values were obtained, especially the data at $1700 \mathrm{deg}$. fahr.

The Piezo Electric effect, I believe was first discussed by C. Treischel ${ }^{3}$ who says in part:

"Now then what happens when we subject this porphyritic structure to the influence of alternating high potential? The theory of probabilities will uphold the statement that a number of these quartz crystals are arranged so that their major axes are at right angles to the direction of the flow of the electric current. The current itself is changing its polarity in accordance with the cyclic change, and during each cyclic change there are points of maximum and zero potential difference. If the current is of 60 cycles there will be 120 maximum potential differences and 120 zero potential differences per second. The effect on each individual crystal, which is arranged with its axis in the right direction, will be a vibratory movement parallel to the direction of the flow of tre displacement current. This effect could cause break down of the dielectric in three different manners: first, a rupturing of the crystals, second, a rupturing of the glassy magma surrounding the crystals; and third, a leakage through the voids between the crystals and the magma when the crystal is at its greatest deformation and the potential difference is at its maximum."

G. I. Gilchrest: I believe that Mr. Peaslee's paper indicates the problem to be more narrow than it is. I am commenting briefly on several portions of his paper.

The tension tests by $\mathrm{Mr}$. Peaslee were made on test pieces with conical ends. Although it is possible

3. "A Possible Cause for the Dielectric Failure of Porcelains which are apparently free from Mechanical Defects." Journal of the American Ceramic Society Vol. 2, No. 2, February 1919. 
to make tension tests on short specimens with conical ends, it is not very satisfactory, as it is difficult to obtain samples that will give uniform results. Various cushioning materials, such as lead, blotting paper, etc., will help to distribute the stress. However, from a consideration of test values obtained from bending tests, tension tests will only indicate about 30 to 50 per cent of the actual tensile strength of the material. Small bars of rectangular cross section tested under bending give the most uniform results.

We recently obtained excellent comparative results from impact tests. The test pieces consisted of small cups having a diameter of 3 in., height of $2 \frac{1}{2}$ in., and thickness of wall of $1 / 2$ in. The cups were placed on side in a $\mathrm{V}$-shaped groove, a round nose plunger free to move in a vertical slide rested on the upper side of the cup. A small weight was dropped on the plunger the height of drop being increased by equal increments until the cups shattered. The tests pieces were easy to manufacture, grinding was not necessary, and the cups were convenient to test. The results are, of course, entirely comparative but where an extensive body investigation is being made, comparative and not quantitative results are desired.

Mr. Peaslee suggests that two bodies are known which can be heated red hot and plunged into water without cracking. Considerable experimental work has been done during the past few years to determine the best body compositions for porcelain used in electrical appliances. There are many bodies being manufactured at the present time that will stand being heated red hot and plunged into water. These bodies, however, are not vitrified to the same degree as the body of our high-tension porcelain insulators. The material is entirely satisfactory for its application, since its function is more that of a mechanical separater than dielectric separater.

Mr. Peaslee suggests detecting over-fired insulators by means of a gage. This method is not practical in an electrical porcelain factory. During firing, the body continues to shrink until it reaches the point of over-vitrification. When the piece is on the edge of over-vitrification, its dimensions are slightly less than when the piece is properly vitrified. When overvitrification commences, the body starts to boil and the material becomes flaky. This condition can be readily detected by the eye.

The degree of porosity can be determined by means of a psycometer or by means of penetration of a colorant material. There is, however, a degree of porosity 
which, apparently, cannot be determined by any known laboratory method. Professor H. J. Ryan of Leland Stanford University obtained some very interesting results which are published in the TRANSACTIONS of the Institute for 1917. Porcelain insulators were found which the megger indicated as porous. These insulators could be dried so that the megger registered infinity. Thereafter, moisture could not be forced back into some of these insulators by any laboratory method tried by Professor Ryan.

Ceramic engineers who have had considerable experience in the production of electrical porcelain, feel that in order to avoid placing material improperly vitrified on the market, a careful check should be kept of the ingredients of the body. It is necessary to keep a careful check on each shipment of raw materials, a check on the prepared body and extremely close control of the firing temperatures. The proper temperature to vitrify the body sufficiently to not allow measurement of porosity should be determined. The temperature at which over-vitrification commences should be determined. The firing control must then be sufficiently close to lie between these two temperatures.

As suggested in Mr. Peaslee's conclusions, the ceramic engineer has his problems before him. He should, however, have the closest cooperation with electrical engineers, as a thorough appreciation of the application of the product is necessary.

W. D. A. Peaslee: I wish to indorse very strongly Mr. Vincent's remarks regarding co-operation between the manufacturer and the electrical engineer. It is very often found that the selection of insulators for a particular condition can be vastly aided by a careful study of operating conditions of lines working under similar conditions, but unfortunately, such operating records are seldom available. It is to be hoped that engineers will keep more and more complete records as time goes on.

With regard to Mr. Spurcks remarks as to the influence of the size and shape of test pieces on the units strength indicated, while it is true that there is a considerable influence, nevertheless, experience has shown that there is a very definite relation between such indications, and that this relation can be determined and relied upon to considerable accuracy.

As to the definition of porosity percentage and means of determining this percentage, it may be remarked that the American Society for Testing Materials, Committee on Electrical Insulating Material, is at 
present actively working on this very problem and I believe it will be of considerable benefit to the industry when these definitions and methods are properly defined.

The figures as to temperature coefficients of resistance are given here merely to show the degree of difference obtainable under identical conditions. The absolute values and precise methods are available but not for publication at present.

With regard to Mr. Gilchrist's statements as to tension tests and the difficulty of obtaining satisfactory results, I cannot agree with him at all, as we have obtained remarkably consistent and satisfactory results with equipment in the hands of untrained laboratory assistants and have not found the bar test in bending any more reliable than the properly conducted tension test.

With regard to the bodies that will withstand extreme temperature changes, I wish to correct Mr. Gilchrist's impression that these are not vitrified with the same degree as the body of his high-tension porcelain insulator. The bodies referred to are vitrified to the same degree, fired at just as high, if not higher, temperatures and make a superior insulating body to any that I have ever seen. The one difficulty in the employment of these bodies for insulators that would be superior to any on the market is the cost. Mr. Gilchrist has certainly received the impression that the body referred to here is a type such as is used for resistance elements, but this is not the case.

With regard to Mr. Gilchrist's remarks on gaging for over vitrification, I think this is one of the subjects to take up in the future to be standardized more fully, for when a ceramic engineer speaks of a vitrified body, unless his standard of vitrification is known, it is a little difficult to tell exactly what he means.

In closing I wish to urge upon all operating engineers the importance of keeping complete and accurate operating records of their insulators and when such records are available on a given type of insulator, these records should be made available to the manufacturer of that insulator. It is only by this sort of co-operation that we can, as insulator manufacturers, gain the most value from experience in the use of our product. 